\title{
Etch selectivities of mask materials for anisotropic dry etching of gas sensing $\mathrm{ZnO}$ and $\mathrm{SnO}_{2}$ films
}

\author{
Jong Cheon Park and Hyun Cho*, \\ Department of Nano Fusion Technology, Pusan National University, Gyeongnam 627-706, Korea \\ *Department of Nanomechatronics Engineering, Pusan National University, Gyeongnam 627-706, Korea \\ (Received July 15, 2011) \\ (Revised August 4, 2011) \\ (Accepted August 5, 2011)
}

\begin{abstract}
Etch selectivities of mask materials to $\mathrm{ZnO}$ and $\mathrm{SnO}_{2}$ films were studied in $\mathrm{BCl}_{3} / \mathrm{Ar}$ and $\mathrm{CF}_{4} / \mathrm{Ar}$ inductively coupled plasmas for fabrication of nanostructure-based gas sensing layer with high aspect ratios. In $25 \mathrm{BCl} / 10 \mathrm{Ar}$ ICP discharges, selectivities of 5.1 6.1 were obtained for $\mathrm{ZnO}$ over $\mathrm{Ni}$ while no practical selectivity was obtained for $\mathrm{ZnO}$ over Al. High selectivities of 7 17 for $\mathrm{ZnO}$ over $\mathrm{Ni}$ were produced in $25 \mathrm{CF}_{4} / 10 \mathrm{Ar}$ mixtures. $\mathrm{SnO}_{2}$ showed much higher etch rates than $\mathrm{Ni}$ and a maximum selectivity of 67 was observed for $\mathrm{SnO}_{2}$ over $\mathrm{Ni}$.
\end{abstract}

Key words Etch selectivity, $\mathrm{SnO}_{2}, \mathrm{ZnO}$, Mask material, ICP etching, Nano gas sensors

\section{가스 센서용 $\mathrm{ZnO}, \mathrm{SnO}_{2}$ 박막의 이방성 식각을 위한 mask 재료의 식각 선택도 조사}

박종천, 조현 *,

부산대학교 나노융합기술학과, 경남, 627-706

*부산대학교 나노메카트로닉스공학과, 경남, 627-706

(2011년 7월 15일 접수)

(2011년 8월 4일 심사완료)

(2011년 8월 5일 게재확정)

요 약 고이온밀도 플라즈마 식각에 의한 고종횡비, 고이방성을 갖는 $\mathrm{ZnO}, \mathrm{SnO}_{2}$ 나노 구조 가스 감응층 형성을 위하여 mask 재료들과의 식각 선택도를 조사하였다. $25 \mathrm{BCl}_{3} / 10 \mathrm{Ar} \mathrm{ICP}$ 플라즈마에서는 $\mathrm{ZnO}$ 와 $\mathrm{Ni}$ 간 5.1 6.1 범위의 식각 선택도가 확보된 반면에 $\mathrm{Al}$ 의 경우 효율적인 식각 선택도를 확보할 수 없었다. $25 \mathrm{CF}_{4} / 10 \mathrm{Ar} \mathrm{ICP}$ 플라즈마에서는 $\mathrm{ZnO}$ 와 $\mathrm{Ni}$ 간에 7 17 범위의 높은 식각 선택도를 얻을 수 있었다. $\mathrm{SnO}_{2}$ 는 $\mathrm{SnF}_{\mathrm{x}}$ 식각 생성물의 높은 휘발성에 기인하여 $\mathrm{Ni}$ 에 비해 매우 높은 식각 속도를 나타내었고, 최고치 약 67의 매우 높은 식각 선택도를 확보하였다.

\section{1. 서 론}

가스 센서는 자동차, 우주항공, 전력, 제철, 등 다양한 산업 분야에 있어서 극한 산업 환경에서의 생산 공정 및 제품의 품질관리, 에너지 효율 관리를 위한 각종 측정 작업을 가능케 할 뿐만 아니라 최근 환경과 건강에 대한 사회적 관심이 급증함에 따라 인체에 유해한 환경에 노 출될 가능성으로부터 인간을 보호하는 소위 "인간의 6 번 째 감각기관"으로서의 기능을 수행한다. 현재 전 세계적

\footnotetext{
Corresponding author

Tel: +82-55-350-5286

Fax: +82-55-350-5289

E-mail: hyuncho@pusan.ac.kr
}

으로 활용되고 있는 가스센서는 $\mathrm{CO}, \mathrm{CO}_{2}, \mathrm{NO}_{\mathrm{x}}, \mathrm{H}_{2}$ 및 $\mathrm{CH}_{4}$ 등의 가스가 존재하는 환경 하에서 발생하는 전기 적 특성 변화를 이용하여 특정 가스 검출이 가능한 $\mathrm{SnO}_{2}$, $\mathrm{ZnO}, \mathrm{TiO}_{2}, \mathrm{Fe}_{2} \mathrm{O}_{3}, \mathrm{WO}_{3}$ 등의 전이금속 산화물을 모재 료(base materials)로 이용하고 있다.

최근 이들 전이금속 산화물의 나노구조를 기반으로 한 가스센서는 더 큰 비표면적을 확보할 수 있어 기존 bulk 형 또는 박막형 가스센서에 비해 더 우수한 가스 감응도 와 선택도 특성을 나타내는 것으로 보고된 이래 나노 가 스센서 소자 개발에 대한 연구가 활발하게 진행되고 있 다. 나노 구조 기반 가스 센서의 제반 특성과 응용성은 나노 구조물의 화학적 조성, 직경, 종횡비, 배향성 등을 얼마나 잘 제어할 수 있느냐에 의해 좌우된다. 현재까지 
보고된 국내 - 외 연구결과에 의하면 많은 연구자들이 구 조 물질의 화학적 조성을 조절하는 것이 가능하고, 비교 적 간단한 실험장치로 나노 구조물 성장이 가능한 상향 식(bottom-up) 방식의 열화학증착공정을 통하여 나노 구 조 기반 가스 센서를 제조하고 있는 추세이다[1-4].

열화학증착공정 등을 이용함으로써 나노 구조물을 제 조하는 상향식 공정은 소자 스케일의 한계를 분자 수준 까지 확대하는 것이 가능한 반면에 기능성 나노 구조물 의 패터닝 및 배향이 쉽지 않아서 나노 구조 제어 범위 가 제한적이고 이들의 성장 재현성 또한 낮은 문제점들 을 안고 있으며, 이를 극복하기 위한 공정기술 개발에 많은 관심이 집중되고 있다[5-7]. 반면에 나노 lithography 공정과 고이온밀도 플라즈마(high density plasma) 식각 공정을 조합한 하향식(top-down) 공정은 기존 상향식 공 정의 단점을 극복할 수 있을 뿐만 아니라 나노 구조 기 반 가스 센서 소자를 대면적으로 생산하는 것이 가능한 기술적 대안으로 부각되었다[8-10].

하향식 공정에 의한 가스 감응 재료의 나노 구조물 형 성에 있어서 핵심공정 중의 하나는 고이온밀도 플라즈마 식각으로 가스 감응층 즉, 미세한 직경을 갖는 나노 구 조물을 높은 종횡비로 형성하는 것이다. 이를 위해서는 가스 감응 재료 층을 빠른 속도로 정밀하게 식각하는 동 시에 높은 이방성과 종횡비를 확보하는 것이 필요하며, 식각 대상물인 산화물 박막과 높은 식각 선택도를 나타 내는 mask 재료를 확보하는 것 또한 중요하다. 본 논문 에서는 나노 가스 센서용 재료로 가장 널리 이용되는 $\mathrm{SnO}_{2}$ 및 $\mathrm{ZnO}$ 박막에 높은 종횡비와 이방성을 갖는 나 노 구조물을 고이온밀도 플라즈마 식각으로 형성하는 공 정에 적합한 mask 재료에 대한 연구를 수행하였다. $\mathrm{BCl}_{3} / \mathrm{Ar}$ 및 $\mathrm{CF}_{4} / \mathrm{Ar}$ 유도결합 플라즈마(ICP)에서 플라즈 마 조성, ICP source power, rf chuck power 등의 공정 변수들을 변화시킨 다양한 조건 하에서 각 mask 재료들 의 식각 선택도를 비교 분석하였다.
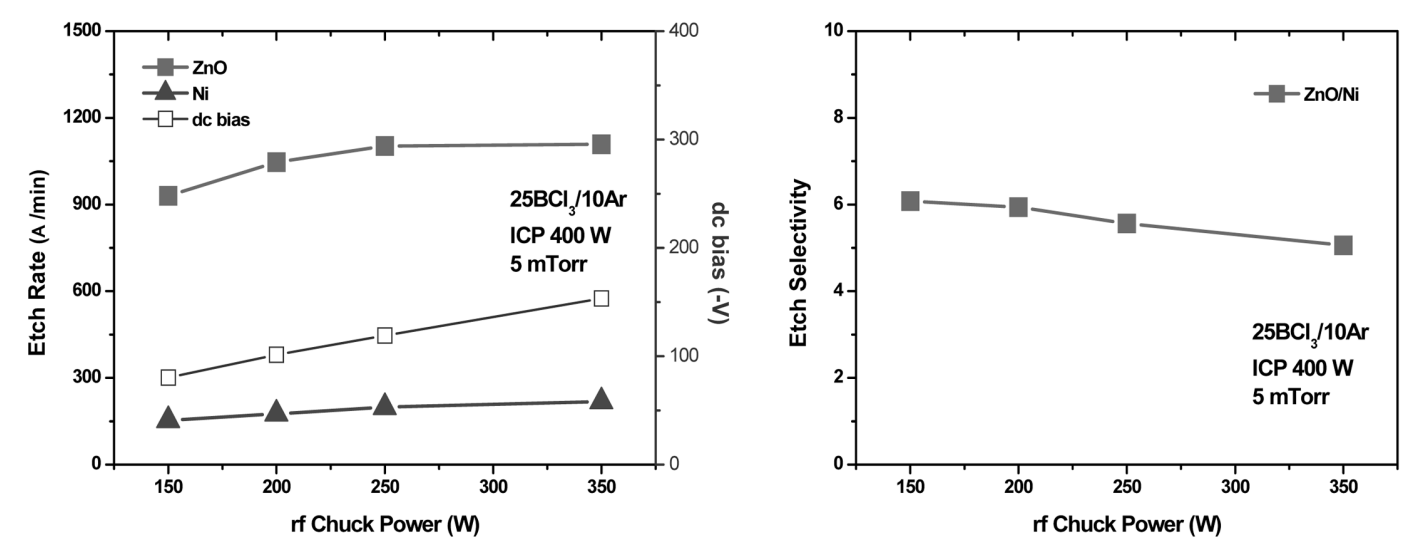

Fig. 1. $\mathrm{ZnO}$ and $\mathrm{Ni}$ etch rates (left), and etch selectivity for $\mathrm{ZnO}$ over $\mathrm{Ni}$ (right) as a function of rf chuck power in $25 \mathrm{BCl}_{3} / 10 \mathrm{Ar}$ ICP

\section{2. 실험과정}

순도 $4 \mathrm{~N}$ 의 산화물 target을 사용하여 직경 4 인치의 $\mathrm{SiO}_{2} / \mathrm{Si}$ 웨이퍼 상에 $\mathrm{SnO}_{2}$ 와 $\mathrm{ZnO}$ 박막을 각각 증착하 였다. 산화물 박막 증착 시 아르곤과 산소 가스를 일정 비율로 섞은 혼합 가스를 스퍼터링 가스로 사용하였고, $30 \mathrm{mTorr}$ 압력, 승온 조건 하에서 $1 \mu \mathrm{m}$ 의 두께로 증착 하였다. 증착된 산화물박막 표면에 photoresist(PR), aluminum 또는 nickel 등의 mask 층을 각각 spin coating, 열/전자빔 증발(thermal/e-beam evaporation)을 통하여 형성한 후 photolithography와 lift-off 공정을 조합한 과 정을 통하여 패터닝하였다. 패터닝된 산화물 박막의 고 이온밀도 플라즈마 식각은 planar type 유도결합플라즈 마(inductively coupled plasma, ICP) 식각장치를 이용하 여 수행하였다. ICP source의 주파수는 $13.56 \mathrm{MHz}$, 최 고 용량은 $1000 \mathrm{~W}$ 이며, 시편은 $13.56 \mathrm{MHz}$, 최고 $450 \mathrm{~W}$ 의 rf power가 연결되고 $\mathrm{He}$ 가스로 냉각되는 chuck위에 위치한 $\mathrm{Si}$ carrier wafer 위에 장착하였다. 식각 가스로 는 $\mathrm{BCl}_{3} / \mathrm{Ar}$ 및 $\mathrm{CF}_{4} / \mathrm{Ar}$ 가스를 각각 사용하였으며 총유 량은 15 35 sccm, 압력은 2 50 mTorr로 유지하였다. 플 라즈마 조성, ICP source power, rf chuck power 및 압 력 등을 변화시킨 다양한 조건 Mask 층을 제거한 후 stylus profilometry, FE-SEM, AFM 등의 장비를 이용하 여 식각 속도, 식각 선택비, 표면 특성 및 측벽각 (sidewall angle) 양상 등을 분석하였다.

\section{3. 결과 및 고찰}

Fig. 1 에 $25 \mathrm{BCl}_{3} / 10 \mathrm{Ar}$ ICP 플라즈마 $(400 \mathrm{~W}$ source power, $5 \mathrm{mTorr}$ )에서 rf chuck power 변화에 따른 $\mathrm{ZnO}$, $\mathrm{Ni}$ 의 식각속도(좌측)와 $\mathrm{ZnO}$ 와 $\mathrm{Ni}$ 간 식각 선택도(우측) 를 나타내었다. Rf chuck power가 증가함에 따라 $\mathrm{ZnO}$

\footnotetext{
discharges ( $400 \mathrm{~W}$ source power, $5 \mathrm{mTorr}$ ).
} 

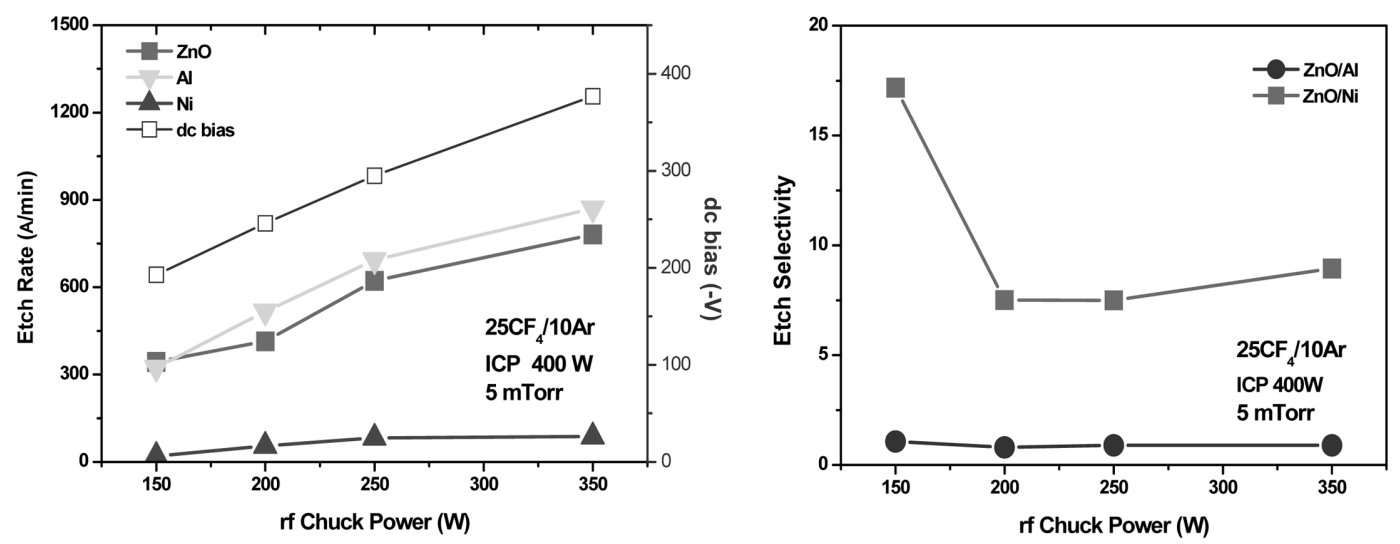

Fig. 2. Material etch rates (left) and etch selectivities for $\mathrm{ZnO} / \mathrm{Al}$ and $\mathrm{ZnO} / \mathrm{Ni}$ (right) in $25 \mathrm{CF}_{4} / 10 \mathrm{Ar}$ ICP discharges $(400 \mathrm{~W}$ or $700 \mathrm{~W}$ source power, 5 mTorr).

와 $\mathrm{Ni}$ 의 식각속도가 처음에는 증가하다가 $200 \mathrm{~W}$ 이상 의 조건에서는 증가세가 둔화되어 주목할 만한 변화를 나타내지 않음을 알 수 있다. 이러한 결과는 이 조건들 하에서의 식각이 플라즈마 내의 chlorine radical과 박막 표면 원자들 간의 화학적 반응에 의해 지배되고 있음을 의미한다. Rf power가 증가함에 따라 플라즈마 내에 존 재하는 이온들이 가지는 평균에너지는 증가하게 되고, 이들 이온들의 포격(ion bombardments)에 의해 플라즈 마 내에서 활성화된 chlorine radical들이 박막 표면에 도달한 후 표면 원자들과의 화학적 반응을 통해 식각 생 성물을 형성하기 이전에 제거되는 결과로 사료된다. $\mathrm{ZnO}$ 가 $\mathrm{Ni}$ 에 비해 더 높은 식각속도를 나타내는 것은 chlorine radical들과 반응을 통해 형성되는 $\mathrm{ZnCl}_{\mathrm{x}}$ 식각 생성물 $\left(\mathrm{ZnCl}_{2}\right.$ : b.p. $\left.756^{\circ} \mathrm{C}\right)$ 이 $\mathrm{NiCl}_{\mathrm{x}}$ 식각 생성물 $\left(\mathrm{NiCl}_{2}\right.$ : m.p. $1001^{\circ} \mathrm{C}$ )에 비해 더 높은 휘발성을 가지기 때문으 로 판단되며 5.1 6.1의 식각 선택도를 나타냄을 확인하 였다. PR mask의 경우 식각 이후 심각한 손상 및 열화 가 진행되어 식각 선택도 측정이 불가능하였다. 또한, $\mathrm{Al}$ 의 경우 $\mathrm{AlCl}_{\mathrm{x}}$ 식각 생성물 $\left(\mathrm{AlCl}_{3}\right.$ : subl. $\left.182.7^{\circ} \mathrm{C}\right)$ 의
휘발성이 $\mathrm{ZnCl}_{\mathrm{x}}$ 식각 생성물보다 더 높기 때문에 $\mathrm{ZnO}$ 보다 더 높은 식각속도를 나타내었다. 따라서 $\mathrm{BCl}_{3} / \mathrm{Ar}$ $\mathrm{ICP}$ 플라즈마 조건하에서는 $\mathrm{Al}$ 이 mask 재료로 적절하 지 않음을 확인하였다.

$25 \mathrm{CF}_{4} / 10 \mathrm{Ar}$ ICP 플라즈마 $(400 \mathrm{~W}$ source power, 5 mTorr)에서 rf chuck power 변화에 따른 $\mathrm{ZnO}, \mathrm{Al}, \mathrm{Ni}$ 의 식각속도(좌측) 및 $\mathrm{ZnO}$ 와 두 mask 재료 간의 식각 선택도(우측)를 Fig. 2에 도시하였다. Fig. 1에 제시한 $25 \mathrm{BCl}_{3} / 10 \mathrm{Ar}$ ICP 플라즈마에서와 달리 rf chuck power 가 증가함에 따라 $\mathrm{ZnO}$ 와 $\mathrm{Al}$ 식각 속도가 계속적으로 증가하는 양상을 나타내고 있다. 이러한 양상은 충분한 농도의 fluorine radical이 이 두 박막의 표면에 공급됨에 따라 $\mathrm{ZnFl}_{\mathrm{x}}\left(\mathrm{ZnF}_{2}\right.$ : b.p. $\left.1500^{\circ} \mathrm{C}\right), \mathrm{AlF}_{\mathrm{x}}\left(\mathrm{AlF}_{3}\right.$ : m.p. $\left.1291^{\circ} \mathrm{C}\right)$ 식각 생성물 형성이 활성화되고, 이온 포격에 의한 후속 적인 식각 반응물 제거가 원활히 진행됨으로써 식각의 화학적 요소(chemical component)와 물리적 요소(physical component)간의 적절한 균형을 이루고 있는 결과로 해 석된다. 그러나 $\mathrm{ZnFl}_{\mathrm{x}}, \mathrm{AlF}_{\mathrm{x}}$ 두 식각 생성물의 휘발성에 있어서 큰 차이가 없기 때문에 거의 동일한 식각 속도가
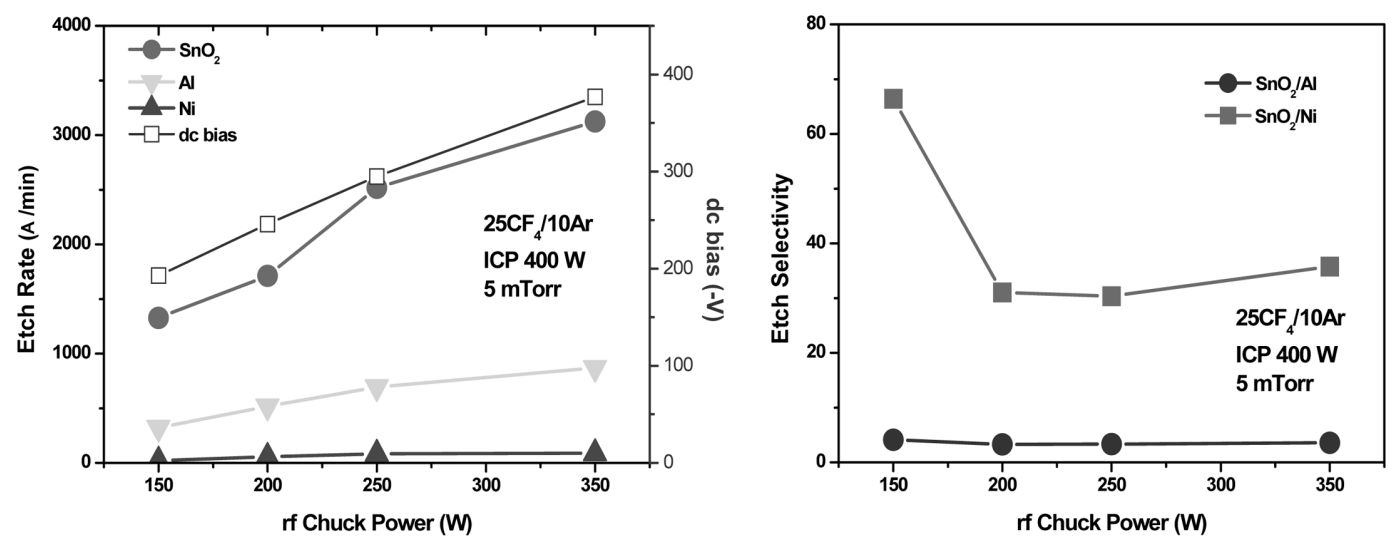

Fig. 3. Material etch rates (left) and etch selectivities for $\mathrm{SnO}_{2} / \mathrm{Al}$ and $\mathrm{SnO}_{2} / \mathrm{Ni}$ (right) in $25 \mathrm{CF}_{4} / 10 \mathrm{Ar}$ ICP discharges $(400 \mathrm{~W}$ or $700 \mathrm{~W}$ source power, 5 mTorr). 

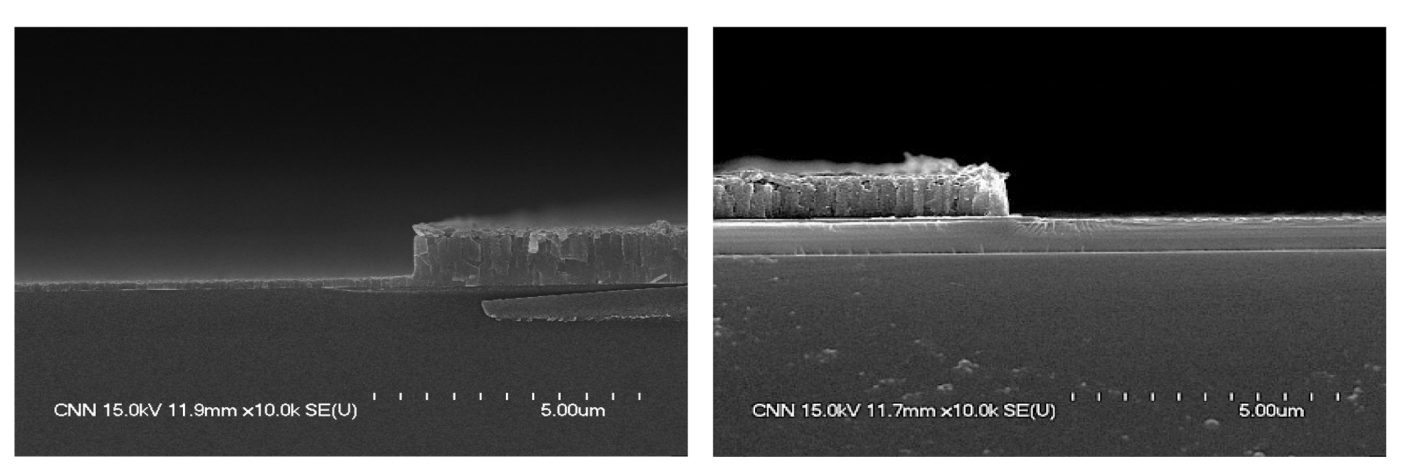

Fig. 4. Cross-sectional FE-SEM micrographs of features etched into $\mathrm{ZnO}$ (left) and $\mathrm{SnO}_{2}$ (right) using $10 \mathrm{CF}_{4} / 5 \mathrm{Ar} \mathrm{ICP}$ discharges (500 W source power, $250 \mathrm{~W}$ rf chuck power, $5 \mathrm{mTorr}$ ).

얻어짐에 따라 1.0 에 근접한 매우 낮은 식각 선택도를 확보할 수 있었다. 반면에 $\mathrm{Ni}$ 의 경우에는 $\mathrm{NiF}_{\mathrm{x}}\left(\mathrm{NiF}_{2}\right.$; b.p. $1750^{\circ} \mathrm{C}$ ) 식각 생성물의 휘발성이 $\mathrm{ZnFl}_{\mathrm{x}}$ 식각 생성물에 비해 상대적으로 낮은 동시에 rf chuck power가 증가하 여도 식각 속도가 현저하게 증가하지 않고 포화되는 경 향을 나타내었다. 그 결과 7 17 범위의 높은 식각 선택 도를 얻을 수 있었다.

Fig. 3은 $25 \mathrm{CF}_{4} / 10 \mathrm{Ar} \mathrm{ICP}$ 플라즈마에서 $\mathrm{rf}$ chuck power 변화에 따른 $\mathrm{SnO}_{2}$ 와 mask 재료들의 식각속도(좌 측)와 $\mathrm{SnO}_{2}$ 와 $\mathrm{Al}, \mathrm{Ni}$ mask 재료 간의 식각 선택도(우 측)를 보여준다. 좌측 그래프에서 보는 바와 같이 $\mathrm{SnO}_{2}$ 식각속도는 rf chuck power에 대한 강한 의존성을 나타 내어 rf chuck power가 증가함에 따라 식각 속도가 지 속적으로 증가하고 있다. 이러한 결과는 Fig. 2에서 설 명한 $\mathrm{ZnO}$ 와 $\mathrm{Al}$ 의 경우와 마찬가지로 $\mathrm{SnF}_{\mathrm{x}}$ 식각 생성 물 $\left(\mathrm{SnF}_{4}\right.$ : subl. $705^{\circ} \mathrm{C}, \mathrm{SnF}_{2}$ : b.p. $\left.853^{\circ} \mathrm{C}\right)$ 형성과 후속 적인 이온도움에 의한 식각 생성물 제거(ion-assisted desorption)간의 균형을 이룰 수 있는 최적의 이온neutral 간 비율이 유지되고 있음을 의미한다. $\mathrm{SnO}_{2}$ 박 막은 $25 \mathrm{CF}_{4} / 10 \mathrm{Ar}$ 플라즈마에서 최고 $3100 \AA / \mathrm{min}$ 의 매 우 높은 식각 속도를 나타내었다. 또한 $\mathrm{SnF}_{\mathrm{x}}$ 식각 생성 물이 $\mathrm{NiF}_{\mathrm{x}}$ 식각 생성물에 비해서 현저하게 높은 휘발성 을 가짐에 따라 최고 67 , 최저 30 의 매우 높은 식각 선 택도를 확보할 수 있었다. $\mathrm{SnO}_{2}$ 와 $\mathrm{Al}$ 간의 경우에는 $\mathrm{Ni}$ 에 비해 크게 낮은 식각 선택도(3.3 4.1)를 얻을 수 있었다.

Fig. 4에 각각 $~ 1500 \AA$ 두께의 $\mathrm{Ni}$ 과 $3000 \AA$ 두께의 $\mathrm{Al}$ 을 mask 층으로 사용하여 $10 \mathrm{CF}_{4} / 5 \mathrm{Ar} \mathrm{ICP}$ 플라즈마 조건 하에서 식각한 $\mathrm{ZnO}$ 및 $\mathrm{SnO}_{2}$ 박막의 단면을 FE$\mathrm{SEM}$ 으로 관찰한 사진을 나타내었다. $\mathrm{Ni}$ 과 $\mathrm{Al}$ mask 층 은 아직 제거되지 않은 상태이며, $\mathrm{ZnO}$ 와 $\mathrm{SnO}_{2}$ 박막의 식각 깊이는 약 $7000 \AA$ 으로 동일하게 형성하였다. 그림 에서 보는 바와 같이 두 가지 식각 구조물 모두 직각에 매우 가까운 측벽각을 유지하고 있으며, 수직한 방향으 로의 식각이 진행되는 동안 측면 방향으로의 식각이 진
행되지 않아 매우 높은 이방성을 나타냄을 알 수 있다. 식각된 바닥면이 평탄한 상태를 유지하고 있어 플라즈마 에 노출된 전면에서 식각이 균일하게 진행되었음을 확인 할 수 있다.

\section{4. 결 론}

하향식 공정으로 $\mathrm{ZnO}, \mathrm{SnO}_{2}$ 나노 가스 센서 소자를 제조를 위한 고이온밀도 플라즈마를 이용한 고종횡비, 고이방성의 나노 구조물 형성에 필수 요소 중의 하나인 mask 재료와의 식각 선택도에 대하여 연구하였다. $25 \mathrm{BCl}_{3} /$ $10 \mathrm{Ar} \mathrm{ICP}$ 플라즈마에서는 $\mathrm{ZnO}$ 와 $\mathrm{Ni}$ 간 5.1 6.1 범위의 식각 선택도가 확보된 반면에 $\mathrm{Al}$ 의 경우 $\mathrm{AlCl}_{\mathrm{x}}$ 식각 생 성물의 높은 휘발성 때문에 mask 재료로 적절하지 않음 을 확인하였다. $25 \mathrm{CF}_{4} / 10 \mathrm{Ar} \mathrm{ICP}$ 플라즈마에서는 $\mathrm{NiF}_{\mathrm{x}}$ 식각 생성물의 휘발성이 $\mathrm{ZnFl}_{\mathrm{x}}$ 식각 생성물에 비해 상대 적으로 낮은 동시에 $\mathrm{rf}$ chuck power에 대한 $\mathrm{Ni}$ 식각 속 도의 의존도가 낮아 7 17 범위의 높은 식각 선택도를 얻을 수 있었다. $\mathrm{SnO}_{2}$ 식각속도는 $\mathrm{SnF}_{\mathrm{x}}$ 식각 생성물 형 성과 이온도움에 의한 식각 생성물 제거 사이의 균형을 이룰 수 있는 최적의 이온-neutral 간 비율을 유지함으로 써 $\mathrm{Ni}$ 에 비해 매우 높은 식각 속도를 나타내었고, 최고 치 약 67의 매우 높은 식각 선택도를 확보하였다. $\mathrm{CF}_{4} /$ $\mathrm{Ar} \mathrm{ICP}$ 플라즈마와 $\mathrm{Ni}$ mask 층을 이용한 고이온밀도 플라즈마 식각은 고종횡비, 고이방성을 갖는 $\mathrm{ZnO}, \mathrm{SnO}_{2}$ 나노 구조 가스 감응층 형성에 매우 높은 응용성을 가지 는 것으로 판단된다.

\section{감사의 글}

이 논문은 2008년도 정부(교육과학기술부)의 재원으로 한국연구재단의 지원을 받아 수행된 기초연구사업 연구 임(D00486). 


\section{참 고 문 헌}

[1] N. Yamazoe and N. Miura, Chemical Sensor Technology Vol. 4 (edited by S. Yamauchi and N. Yamazoe, Kodansa-Elseveir, Tokyo, 1992) pp. 19-42.

[ 2 ] Z. Fan, D. Wang, P.-C. Chang, W.-Y. Tseng and J.G. Lu, "ZnO nanowire field-effect transistors and oxygen sensing properties", Appl. Phys. Lett. 85 (2005) 5923.

[ 3 ] Q. Wan, Q.H. Li, Y.J. Chen, T.H. Wang, X.L. He, J.P. $\mathrm{Li}$ and C.L. Lin, "Fabrication and ethnol sensing characteristics of $\mathrm{ZnO}$ nanowire gas sensors", Appl. Phys. Lett. 84 (2004) 3654.

[ 4 ] M.H. Huang, Y. Wu, H. Feick, N. Tran, E. Weber and P. Yang, "Catalytic growth of zinc oxide nanowires by vapor transpport", Adv. Mater. 13 (2001) 113.

[ 5 ] P. Parthangal, R. Cavicchi and M.R. Zachariah, "A universal approach to electrically connecting nanowire arrays using nanoparticles-application to a novel gas sensor architecture", Nanotechnology 17 (2006) 3786.

[6] Y. Cao, W. Liu, J. Sun, Y. Han, J. Zhang, S. Liu, H. Sun and J. Guo, "A technique for controlling the align- ment of silver nanowires with an electric field", Nanotechnology 17 (2006) 2378.

[7] H.C. Kim, J.H. Kim, H.J. Yang, J.S. Suh, T.Y. Kim, B.W. Han, S.W. Kim, D.S. Kim, P.V. Pikhitsa and M.S. Choi, "Parallel patterning of nanoparticles via electrodynamic focusing of charged aerosols", Nature Nanotechnology 1 (2006) 117.

[ 8 ] A. Tsujiko, T. Kisumi, Y. Magari, K. Murakoshi and Y. Nakato, "Selective formation of nanoholes with (100)face walls by photoetching of $\mathrm{n}-\mathrm{TiO}_{2}$ (rutile) electrode, accompanied by increases in water-oxidation photocurrent", J. Phys. Chem. B 104 (2000) 4873.

[9] S.A. Akbar, C. Carney, S.H. Yoon and K. Sandhage, "Ceramic nanostructures by gas phase reaction", 209th The Electrochemical Society Meeting, Abstract \#794 (2006).

[10] Y.I. Bang, K.D. Song, B.S. Joo, J.S. Huh, S.D. Choi and D.D. Lee, "Thin film micro carbon dioxide sensor using MEMS process", Sensors and Actuators B 102 (2004) 20. 